\title{
Bacterial species and their associations with acute and chronic mastitis in suckler ewes
}

\author{
E. M. Smith, ${ }^{* 1}$ Z. N. Willis, ${ }^{*}$ M. Blakeley, ${ }^{* 2}$ F. Lovatt, †‡ K. J. Purdy, ${ }^{*}$ and L. E. Green ${ }^{\star}$ \\ *School of Life Sciences, University of Warwick, Gibbet Hill Road, Coventry, CV4 7AL, United Kingdom \\ †University of Nottingham, Sutton Bonington, Loughborough, LE12 5RD, United Kingdom \\ ¥Flock Health Ltd., Balmer House, Eggleston, Co. Durham, DL12 OAN, United Kingdom
}

\section{ABSTRACT}

Acute mastitis in suckler ewes is often detected because of systemic signs such as anorexia or lameness, whereas chronic mastitis, characterized by intramammary abscesses with no systemic disease, is typically detected when ewes are inspected before mating. The aims of the current study were to identify the species and strains of culturable bacteria associated with acutely diseased, chronically diseased, and unaffected mammary glands to investigate whether species and strains vary by state. To investigate acute mastitis, 28 milk samples were obtained from both glands of 14 ewes with acute mastitis in one gland only. To investigate chronic mastitis, 16 ovine udders were obtained from 2 abattoirs; milk was aspirated from the 32 glands where possible, and the udders were sectioned to expose intramammary abscesses, which were swab sampled. All milk and swab samples were cultured aerobically. In total, 37 bacterial species were identified, 4 from acute mastitis, 26 from chronic mastitis, and 8 from apparently healthy glands. In chronic mastitis, the overall coincidence index of overlap of species detected in intramammary abscesses and milk was 0.60 , reducing to 0.36 within individual glands, indicating a high degree of species overlap in milk and abscesses overall, but less overlap within specific glands. Staphylococcus aureus was detected frequently in all sample types; it was isolated from 10/14 glands with acute mastitis. In 5 ewes, closely related strains were present in both affected and unaffected glands. In chronic mastitis, closely related Staphylococcus aureus strains were detected in milk and abscesses from the same gland.

Received April 13, 2015.

Accepted June 19, 2015.

${ }^{1}$ Corresponding author: edward.smith@warwick.ac.uk

${ }^{2}$ Present address: Salivary Research Unit, King's College London Dental Institute, London, SE1 9RT, United Kingdom.
Key words: suckler ewe, acute mastitis, chronic mastitis, Staphylococcus aureus, matrix-assisted laser desorption/ionization time-of-flight (MALDI-ToF)

\section{INTRODUCTION}

Intramammary infections in suckler ewes are usually caused by bacterial infection of the mammary gland. The IMI can have a wide range of presentations from no detectable clinical abnormality (subclinical disease) to a hot swollen gland and, occasionally, sudden death (acute mastitis). The incidence of acute clinical mastitis ranges from 0 to $6.6 \%$ of sheep per flock (Onnasch et al., 2002; Arsenault et al., 2008).

Intramammary abscesses are a presentation of chronic mastitis and thought to form following an IMI, although not all IMI lead to abscess formation. These abscesses are often only detected when a gland is palpated, typically when farmers inspect ewes at the end of lactation, or when selecting ewes for mating. Few reports are available on the prevalence of ewes with intramammary abscesses. Onnasch et al. (2002) reported a prevalence of chronic mastitis of $2.8 \%$, and Saratsis et al. (1998) reported abnormalities (including nodules, lumps, diffuse hardness, abscesses, and cysts) in the udders of 162/3,529 (4.6\%) ewes. Anecdotally, British farmers indicate that 20 to $30 \%$ of ewes culled from the flock (i.e., $4-6 \%$ of the total flock if $20 \%$ are culled) at weaning have intramammary abscesses.

More than 130 bacterial species have been associated with IMI in dairy cows (Watts, 1988) and 20 to 30 with IMI in suckler sheep to date (Mørk et al., 2007; Arsenault et al., 2008; Marogna et al., 2010). The main organisms associated with acute mastitis in sheep are Staphylococcus aureus, Mannheimia haemolytica, Streptococcus uberis, and Escherichia coli. In dairy ewes, signs of chronic mastitis defined as nodules, abscesses, sclerosis, and atrophy have been significantly associated with isolation of Staph. aureus from milk (Marogna et al., 2010), and Onnasch et al. (2002) stated that the most frequently isolated pathogens from cases of 
chronic mastitis were Staph. aureus, Streptococcus species, and Arcanobacter pyogenes. Abscesses that result from infection with the endogenous flora of a body site are reported to be polymicrobial (Brook, 2002), and it is hypothesized that polymicrobial abscesses persist, in part, because the species act synergistically.

The aims of the current study were to characterize the culturable bacterial species associated with acute mastitis and associated unaffected glands, and intramammary abscesses (chronic mastitis) and associated milk, of suckler ewes to investigate whether species and strains were common or varied between these presentations.

\section{MATERIALS AND METHODS}

\section{Sample Collection and Bacterial Isolation}

Study 1: Investigation of Acute Mastitis. Milk samples were aseptically collected from both glands of 14 sheep with acute clinical mastitis in one gland only. Glycerol (final concentration $\sim 10 \% \mathrm{vol} / \mathrm{vol}$ ) was included in each sample as a cryopreservant (Smith et al., 2011), and all samples were stored at $-20^{\circ} \mathrm{C}$ until culture. One hundred microliters of each sample was spread across the surface of a brain heart infusion (BHI) agar plate containing 5\% sheep blood and incubated at $37^{\circ} \mathrm{C}$ for $48 \mathrm{~h}$. Growth was observed at 24 and $48 \mathrm{~h}$ and the number of colony-forming units estimated for each morphologically distinct colony type; within a sample, unique morphological types were considered to be a single species. Where colony-forming units were too numerous to count, a figure of 1,000 cfu was used for calculations. One example of each morphologically distinct colony type per sample was purified by streaking across a second BHI agar plate containing 5\% sheep blood to produce isolated colonies, and stored at $-80^{\circ} \mathrm{C}$.

Study 2: Investigation of Chronic Mastitis. Sixteen ovine udders (32 glands, 2 glands per udder) were obtained from 2 abattoirs in England. On arrival at the laboratory, each udder's surface was thoroughly cleaned with $70 \%$ ethanol, and one sample of milk was aspirated from each gland where possible, using a sterile 18 -gauge needle and syringe. One hundred microliters of each milk sample was cultured as described above. Each gland was then sliced into parasagittal sections using a sterile blade, sterilized between cuts with $70 \%$ ethanol. The number of abscesses was recorded, and each abscess was swabbed using a sterile cotton-tipped swab that was immediately plated on a BHI agar plate containing $5 \%$ sheep blood and incubated at $37^{\circ} \mathrm{C}$ for $48 \mathrm{~h}$. Morphologically distinct colony types were purified and stored at $-80^{\circ} \mathrm{C}$ as described above.

\section{Identification of Bacterial Isolates}

Matrix-assisted laser desorption/ionization time-offlight (MALDI-ToF) mass spectrometry was used to identify isolates (Alatoom et al., 2011). Pure isolates were cultured on BHI agar and a loop of each isolate was suspended in $75 \%$ ethanol and pelleted at $>20,000$ $\times g$ for $5 \mathrm{~min}$ at room temperature; the supernatant was discarded and the pellet resuspended in 1 volume (equal to pellet size) of $70 \%$ formic acid (Sigma-Aldrich Company Ltd., Dorset, UK) and 1 volume of acetonitrile (Sigma-Aldrich Company Ltd.). Samples were then pelleted at $>20,000 \times g$ for 2 min at room temperature, $1 \mu \mathrm{L}$ of supernatant was placed in a well on a steel target plate (Bruker UK Ltd., Coventry, UK) and air-dried. Once dry, $1 \mu \mathrm{L}$ of $\alpha$-cyano-4-hydroxycinnamic acid matrix (Bruker UK Ltd.) was overlaid on each sample and air dried.

Target plates were loaded into a Microflex LT instrument (Bruker UK Ltd.) with protein mass profiles obtained using the MALDI Biotyper wizard classification and FlexControl software (Bruker UK Ltd.) with default settings. The MALDI Biotyper compares the spectra obtained with a database of known species [February 2014 update: 5,627 isolates, 1,951 species in 388 genera, with 20 to 24 replicates per (predominantly human) isolate] and produces a top-10 list of matches for each sample plus a confidence score (range: $0-3$ ). Using the recommended cut-off values, a score $\geq 2.30$ indicates highly probable species identification, a score of 2.00 to 2.29 indicates probable species identification, and scores of 1.70 to 1.99 indicate probable genus identification (Bruker Daltonik GmbH, 2011). Scores $<1.70$ are not considered a reliable identification. To overcome the lack of veterinary isolates for some species in the database, the criteria used in the current study were modified for isolates with a score of 1.70 to 1.99 . If $\leq 3$ of the identified species were in the database, the species designation was accepted. If $>3$ species were in the database and the top $\geq 3$ identifications were the same species, then the species designation was also accepted. For all cases outside of these criteria, only the genus designation was accepted.

Where species were not identifiable using MALDIToF, DNA was extracted from overnight cultures using the NucleoSpin Tissue Kit (Machery-Nagel GmbH \& Co. KG, Düren, Germany) as recommended. The $16 \mathrm{~S}$ gene was amplified using primers $27 \mathrm{~F}$ and $1525 \mathrm{R}$ and sequenced using the internal primers PSL and PSR (Moore et al., 2008). Sequences were assembled in SeqMan Pro (DNASTAR Inc., Madison, WI), manually trimmed, and compared with the National Center for Biotechnology Information 16S ribosomal RNA se- 
quences database (http://blast.ncbi.nlm.nih.gov/Blast. cgi). The species designation was accepted when the identity and query coverage were $\geq 96 \%$.

For the isolates identified by sequencing $(\mathrm{n}=36)$, no provisional identification was made by the Biotyper because all scores were $<1.70$; one isolate had a score of zero, indicating the extraction or loading had failed. In total, 11 species were identified, 8 of which are represented in the current database by 1 to 12 isolates (Supplementary Table S1; http://dx.doi.org/10.3168/ jds.2015-9702). One of the species identified by sequencing (Staphylococcus lentus) was also identified by the Biotyper in another sample; however, the remaining 10 species were only identified by sequencing.

\section{Data Analysis}

Study 1: Investigation of Acute Mastitis. All data were entered into an Excel spreadsheet [2010, version: 14.0.6129.5000 (32-bit); Microsoft Corp., Redmond, WA]. To investigate differences between diseased and unaffected glands, total $\log _{10}$ colony-forming units per milliliter for each gland were calculated and analyzed with F-tests and $t$-tests in Excel. For culturenegative glands, a $\log _{10}$ value of zero (equivalent to 1 cfu) was used for all calculations. The distribution of species and bacterial load by disease status, and the number of ewes with bilateral infection with the same species was calculated.

Spectral analysis to investigate Staphylococcus aureus diversity was performed in MicrobeMS (Lasch et al., 2014). All spectra were preprocessed, including smoothing, baseline correction, and normalization; peak detection was set to 100 peaks per spectrum, and all spectra were calibrated using an internally generated list of 30 peaks at mass-to-charge-ratios $(\mathrm{m} / z)$ ranging from 2,149.7478 to 8,090.5314 (Supplementary Table S2; http://dx.doi.org/10.3168/jds.2015-9702). Spectral peak tables were converted to bar code spectra and analyzed using hierarchical cluster analysis. The mass tolerance was set to $200 \mathrm{ppm}$, and spectra were clustered using Euclidean distances and average linkage (Lasch et al., 2014), with output visualized as a dendrogram. Clusters were defined using an arbitrary spectral distance cut-off value of 22. Strains from the same sample were indicated on the dendrogram. Fisher's exact tests were used to examine the distribution of isolate source by cluster (http://vassarstats.net/tab2x2.html).

Study 2: Investigation of Chronic Mastitis. All data were entered into an Excel spreadsheet, and the distributions of abscesses and isolates overall by ewe (udder) and by gland were calculated. Where more than one bacterial species was detected in a sample, the numerically dominant species was defined as one that had $>50 \% \mathrm{cfu}$. Where this threshold was not reached, no dominant species was identified. Staphylococcus aureus diversity was investigated using spectral analysis as described for study 1.

In the chronic mastitis udders, the coincidence index of overlap (Dice, 1945) was calculated overall and by ewe and mammary gland to quantify the overlap between 2 environments (milk and abscesses) using a range from 0 , no overlap, to 1 , complete overlap of species between environments. This was determined using the formula: $(2 b) /(a+m+b)$, where $b=$ number of species in both abscess and milk samples, $a=$ number of species in abscess samples, and $m=$ number of species in milk samples.

\section{RESULTS}

\section{Study 1: Investigation of Acute Mastitis}

A total of 28 milk samples were farmer collected from 14 ewes within 2 mo of lambing, from 6 commercial farms (1-5 ewes/farm) in a 20-mile diameter area of northeast England. The sample set consisted of 14 matched pairs from diseased and unaffected mammary glands. The number of culture-negative samples was 6/28, 2 from affected and 4 from unaffected glands. From the remaining 22 samples, 46 morphologically distinct isolates were detected; 2 failed to grow on subculture, and the remaining 44 were identified using the MALDI Biotyper $(\mathrm{n}=41 ; 93.2 \%)$ or $16 \mathrm{~S}$ sequencing ( $\mathrm{n}$ $=3 ; 6.8 \%$ ).

Of the 12 culture-positive samples from diseased mammary glands, a single bacterial species was detected in each of 9 samples, and 2 species in each of the remaining 3 . Of the 10 culture-positive samples from unaffected glands, 5 contained a single species, 3 contained 2 species, and single samples were present containing 3 and 4 species of bacteria, respectively (Figure 1A). Nine species were identified in total among mastitis and unaffected glands, 4 in affected glands and 8 in unaffected glands (Table 1). Bacterial load varied between ewes; however, no significant difference $(P>$ 0.05 ) was found in the numbers of colony-forming units per milliliter detected in diseased and unaffected glands (Supplementary Table S3; http://dx.doi.org/10.3168/ jds.2015-9702).

Staphylococcus aureus was the most frequently isolated species, detected in 10/12 affected samples, and $6 / 10$ unaffected samples. It was detected bilaterally in 6 ewes, and an additional 4 ewes had Staph. aureus in the diseased gland only. Analysis of Staph. aureus mass spectra from diseased and unaffected glands suggested the presence of 3 clusters of 3 to 16 isolates (Figure 1B). The largest cluster (cluster III) contained isolates from 
A
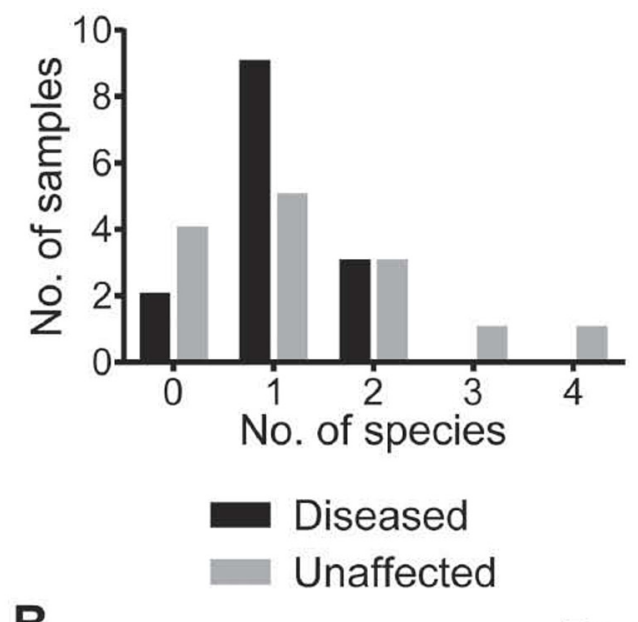

B

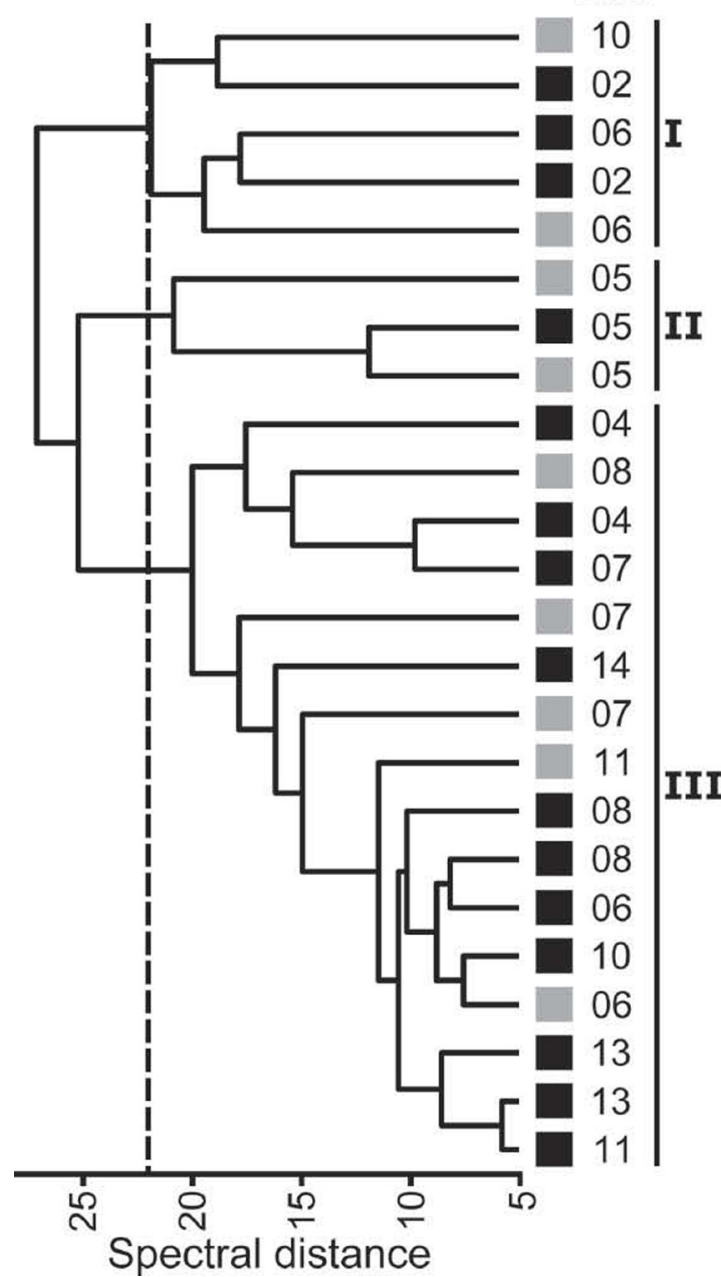

Figure 1. Study 1: (A) Distribution of distinct isolated species from diseased and unaffected milk samples, and (B) hierarchical cluster analysis of matrix-assisted laser desorption ionization time-of-flight mass spectra of Staphylococcus aureus isolated from diseased and unaffected mammary glands of ewes with acute clinical mastitis. The indicated clusters (I, II, and III) are defined at a spectral distance cut-off of 22 . all farms, and diseased and unaffected glands. Cluster I contained 5 isolates, 4 from 2 ewes on a single farm, with representatives from both diseased and unaffected glands. The smallest cluster (cluster II) contained 3 isolates from the diseased and unaffected glands of one ewe. Of the 6 ewes where Staph. aureus was isolated bilaterally (ewe 05, 06, 07, 08, 10, and 11), isolates from both glands of 5 ewes were present in the same cluster. However, for 1 ewe (ewe 10), the isolate from the unaffected gland (cluster I) differed from the one detected in the diseased gland (cluster III; Figure 1B).

\section{Study 2: Investigation of Chronic Mastitis}

Five udders had no intramammary abscesses; the remaining 11 had abscesses in 15 glands (4 ewes had abscesses in both glands), and 33 intramammary abscesses were detected in total (Table 2). Abscess morphologies ranged from 1- to 2-cm diameter pus-filled abscesses to a 6 - to 7 -cm diameter intramammary void intersected by fibrous strands (Supplementary Images S1 and S2; http://dx.doi.org/10.3168/jds.2015-9702). In total, 29/33 abscesses were culture positive and 87 morphologically distinct isolates were identified. Six isolates failed to grow on subculture; the remaining 81 were identified using the MALDI Biotyper $(\mathrm{n}=63$; $77.8 \%)$ or $16 \mathrm{~S}$ sequencing $(\mathrm{n}=18 ; 22.2 \%)$. In total 26 species were identified in abscesses (Tables 2 and 3 ).

An overdispersed Poisson distribution was found of number of species within abscesses $($ mean $=1.9$; variance $=3.1$; Figure $2 \mathrm{~A}$ ); the modal number of species detected was 1 in 16 abscesses, with a maximum of 7 species in one abscess. A numerically dominant species was identified in 4 abscesses with $>1$ species present, and a weak positive relationship was observed between the numbers of abscesses and number of bacterial species detected within abscesses in a mammary gland. Staphylococcus aureus was the most frequently detected species, present in abscesses in 7 glands from 5 udders. Streptococcus uberis was detected in abscesses from 4 glands from 4 udders; no other species were detected in more than 3 udders (Table 3). Staphylococcus aureus was the only cultured organism detected in 4 abscesses, and was the dominant species in one further abscess. Streptococcus ovis was the only cultured organism detected in 2 abscesses, and Pseudomonas aeruginosa dominated 2 mixed cultures, including one sample from an intramammary void (Supplementary Image S2; http://dx.doi.org/10.3168/jds.2015-9702). No other species was the only cultured organism detected or dominated more than one abscess (Table 3 ).

Twenty-four milk samples were aspirated from 15/16 udders; 2 milk samples were obtained from 9 udders, and one milk sample from 6 udders (Table 2). Fifteen 
Table 1. Study 1: frequency of bacterial species isolated from 28 glands of 14 ewes, each with acute mastitis in one gland only

\begin{tabular}{lcc}
\hline Species & $\begin{array}{c}\text { Glands with } \\
\text { acute mastitis } \\
(\mathrm{n}=14)\end{array}$ & $\begin{array}{c}\text { Unaffected } \\
\text { glands } \\
(\mathrm{n}=14)\end{array}$ \\
\hline Bacillus licheniformis & 2 & 4 \\
Bacillus subtilis & & 1 \\
Escherichia coli & & 1 \\
Macrococcus caseolyticus & 10 & 1 \\
Staphylococcus aureus & 1 & 6 \\
Staphylococcus chromogenes & 1 & 2 \\
Staphylococcus cohnii & & \\
Staphylococcus succinus & & 1 \\
Staphylococcus warneri & 2 & 4 \\
No growth detected & 1 & 1 \\
Unidentified & & \\
\hline
\end{tabular}

milk samples from 10 udders were culture positive, yielding 55 bacterial isolates. Forty isolates $(72.7 \%)$ were identified using the MALDI Biotyper and 15 $(27.3 \%)$ by $16 \mathrm{~S}$ sequencing. In total, 24 species were identified; 5 samples each contained a single species, and $2,4,1,1$, and 2 samples each contained $2,3,4,5$, and 6 species, respectively (Figure 2A).

Staphylococcus chromogenes was the species most frequently isolated from milk, detected in 5 glands from 5 udders (Table 3 ). Numerically dominant species were identified in 12 milk samples, although no one species dominated more than 2 samples (Table 3 ). In 6 mammary glands where a dominant species was identified in milk, abscesses were also present. In 4 of these, the dominant species in milk was also detected in an abscess from the same gland.

In total, 35 bacterial species were identified; 11 were detected only in abscesses, 9 only in milk and 15 in both abscesses and milk (Table 3). The coincidence index of overlap between milk and abscess samples overall, irrespective of ewe and gland, was 0.60 ; by ewe $(n=10$ udders) the value was 0.38 , and by mammary gland (n $=11$ ) the value was 0.36 .

Analysis of Staph. aureus mass spectra suggested one singleton isolate and 2 clusters of 6 and 13 isolates were present within the abscess and aspirated milk samples (Figure 2B). Both clusters contained isolates from more than one udder. The 4 isolates detected in milk were in the same clusters as isolates detected in abscesses from the same udders (udders L and M; Figure 2B). More than one Staph. aureus strain was isolated from 4 abscesses and one milk sample, and with the exception of one abscess sample, strains from the same sample were located in separate clusters (Figure 2B).

When the Staph. aureus spectral profiles from the 2 studies were combined, 2 singletons and 3 clusters of 3 to 32 isolates were detected (Supplementary Figure S1; 10.3168/jds.2015-9702). Clusters I $(\mathrm{n}=7)$ and III $(\mathrm{n}=$ 32 ) contained isolates from both studies, whereas cluster II $(\mathrm{n}=3)$ contained isolates from one ewe from study 1. No significant difference $(P>0.05)$ was found in the origin of the Staph. aureus sources [abscess or aspirated milk (study 1); and diseased or unaffected gland (study 2 )] between the 2 main clusters. This was also true for subclades A and B in cluster 3 (Supplementary Figure S1; http://dx.doi.org/10.3168/jds.2015-9702).

\section{DISCUSSION}

This is the first study to investigate the culturable bacterial species associated with cases of acute clini-

Table 2. Study 2: numbers of samples collected and bacterial species detected, by udder and mammary gland ${ }^{1}$

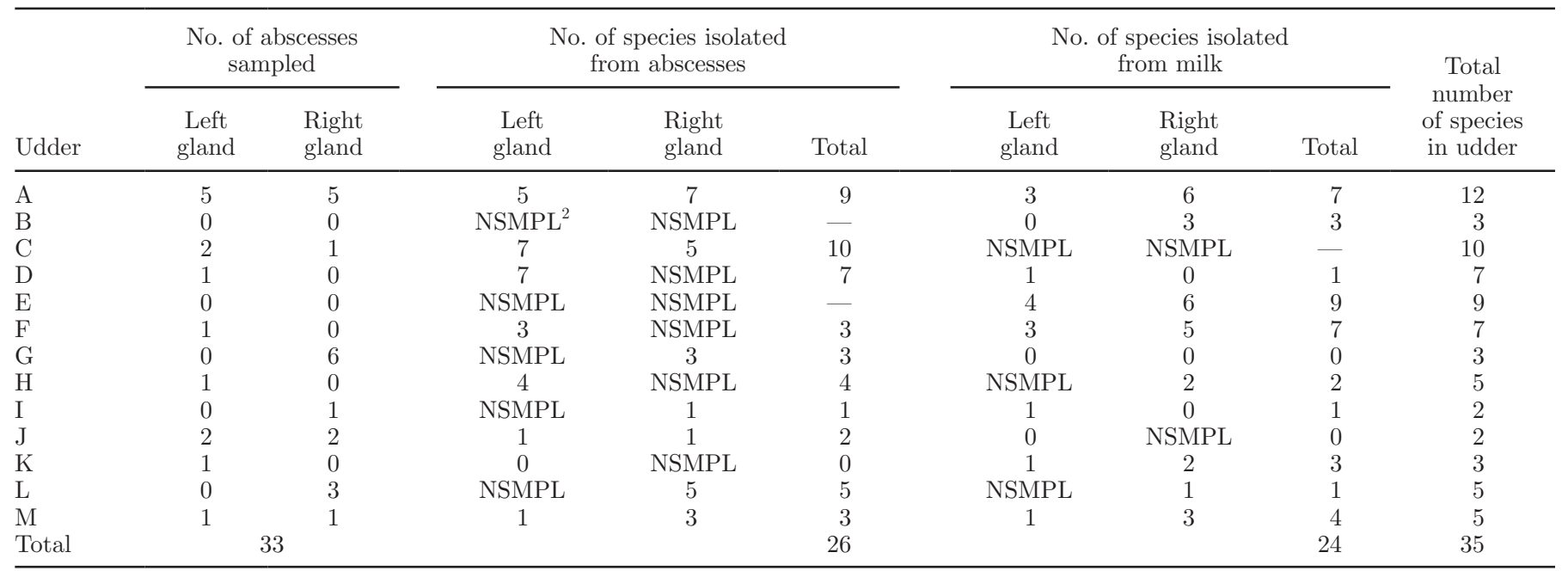

${ }^{1}$ Three additional udders contained no visible abscesses, and no bacteria were cultured from aspirated milk samples from these udders.

${ }^{2} \mathrm{NSMPL}=$ no sample. 
Table 3. Study 2: number of abscesses, glands, and udders in which each species was detected from the abscesses and milk of 14 udders

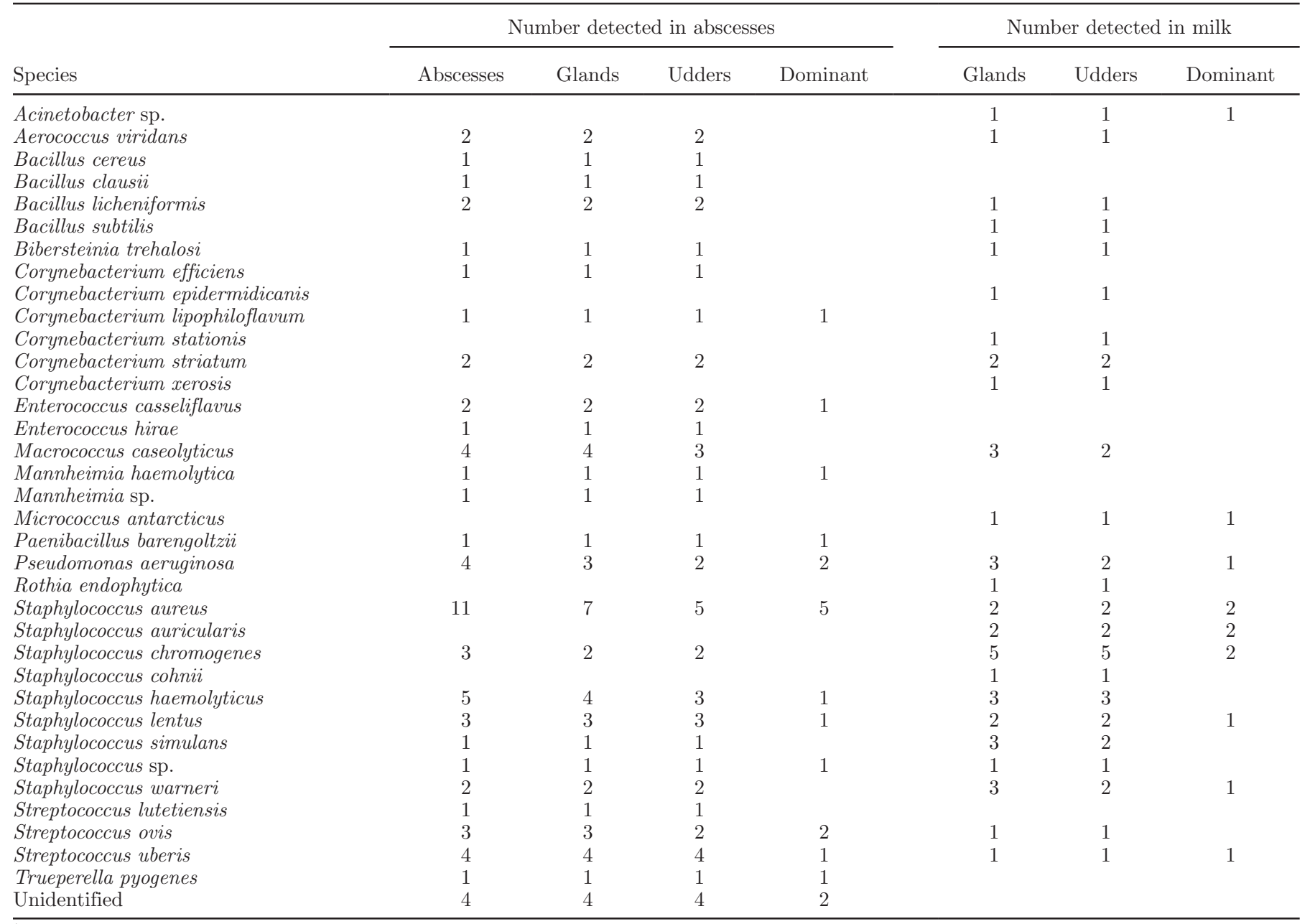

${ }^{1}$ Dominant refers to one organism representing $>50 \%$ of bacterial plate count, based on morphology.

cal mastitis and the paired unaffected glands of suckler ewes, and from intramammary abscesses and associated milk samples. A total of 37 bacterial species were cultured from the samples in the study. Although some species were more prevalent than others, no clear difference was present in species detected in acute mastitis, intramammary abscesses, or associated milk samples (Tables 1 and 3). The coincidence index value of 0.60 in study 2 highlights the strong species overlap between abscesses and milk, and therefore the lack of species niche-specificity to a situation (chronic mastitis, milk). The lower similarity index within individual mammary glands with chronic mastitis might be explained by the fact that the bacterial community in a closed abscess is likely to remain more stable than the bacterial community in milk, where bacteria might leave or arrive via the teat.

The overdispersed Poisson distribution of species from abscesses and associated milk samples suggests a random number of species in any one sample (Figure $2 \mathrm{~A}$ ). Visually, a suggestion is present that the number of species cultured was lower in acute mastitis samples, than the paired mammary gland (Figure 1A), suggesting a dominance of one species during acute disease. This reduction in number of species during disease is also reported in studies of intramammary microbial communities (Hunt et al., 2011; Kuehn et al., 2013) and in other studies of healthy and diseased sites such as the ovine foot (Calvo-Bado et al., 2011). The variation in bacterial load between ewes was similar to a previous report investigating sheep milk samples (Smith et al., 2011). Approximately $20 \%$ of samples $(6 / 28)$ produced no growth in the current study compared with $18 / 80$ previously; however, a higher proportion of milk samples with high bacterial loads $(>100 \mathrm{cfu} / \mathrm{mL})$ was present in the current study (54\% vs. 38\%; Smith et al., 2011). This was probably due to analysis of acute clinical mastitis rather than cross-sectional samples collected on 
a single day, and is supported by the nonsignificantly higher average bacterial load in diseased glands compared with unaffected glands (Supplementary Table S3; http://dx.doi.org/10.3168/jds.2015-9702).

Previous work has suggested that abscesses are generally polymicrobial (Brook, 2002), and that a community of species assists in abscess formation and persistence. This is known as a staphylococcal abscess community (SAC) in abscesses caused by staphylococci (particularly Staph. aureus). The SAC is protected by a fibrincontaining pseudocapsule, which allows the abscess to mature and evade host defenses (Cheng et al., 2010, 2011). Subsequently, the abscess can rupture, releasing the pathogen community to repeat the process. Abscess rupture can result in fibrotic scars (Cheng et al., 2011), and the varying stages of abscess maturation and rupture might explain some of the phenotypic diversity in abscesses in the current study (Supplementary Images S1 and S2; http://dx.doi.org/10.3168/jds.2015-9702).

Whereas $40 \%$ of abscesses had polymicrobial communities, almost $60 \%(17 / 29)$ of abscesses produced a pure culture. This potentially challenges the hypothesis that abscesses form as polymicrobial communities as a result of introduction of the endogenous flora into a normally sterile body site (Brook, 2002). Samples were, however, only cultured aerobically, and anaerobic bacteria commonly outnumber aerobic species in abscesses (Brook, 2002). Anaerobic species such as Fusobacterium necrophorum have been detected in bovine intramammary microbiome studies and human abscesses (Brook, 2002; Oikonomou et al., 2012), so it is possible that these species were present, but not detected by aerobic culture. No data are currently available on the endogenous flora of ovine mammary glands; however, a study of bovine healthy, subclinically and clinically diseased quarters indicates that the endogenous flora of healthy quarters is similar to that detected in subclinical infections (Oikonomou et al., 2014). This suggests that a variety of species might be present in the gland at the time of abscess formation.

Staphylococcus aureus dominated all sample types: milk from acute mastitis and the paired unaffected gland, and from swabs of abscesses and associated milk. Other authors have reported that Staph. aureus is commonly associated with acute and chronic mastitis in suckler ewes (Jones and Watkins, 1998; Onnasch et al., 2002; Mørk et al., 2007), but the current study is the first to report Staph. aureus in chronic mastitis abscesses and an associated milk sample from the same gland. The detection of closely related strains of Staph. aureus bilaterally in ewes with acute mastitis also suggests colonization by closely related strains within ewes. Based on mass spectra analysis, Staph. aureus strains did not vary by sample type, suggesting that no spe-
A
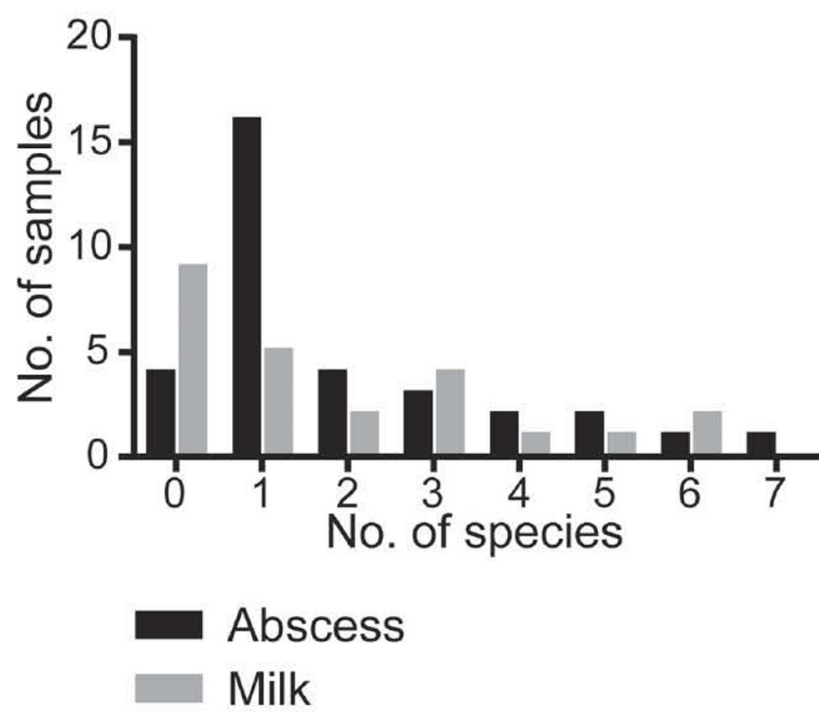

B

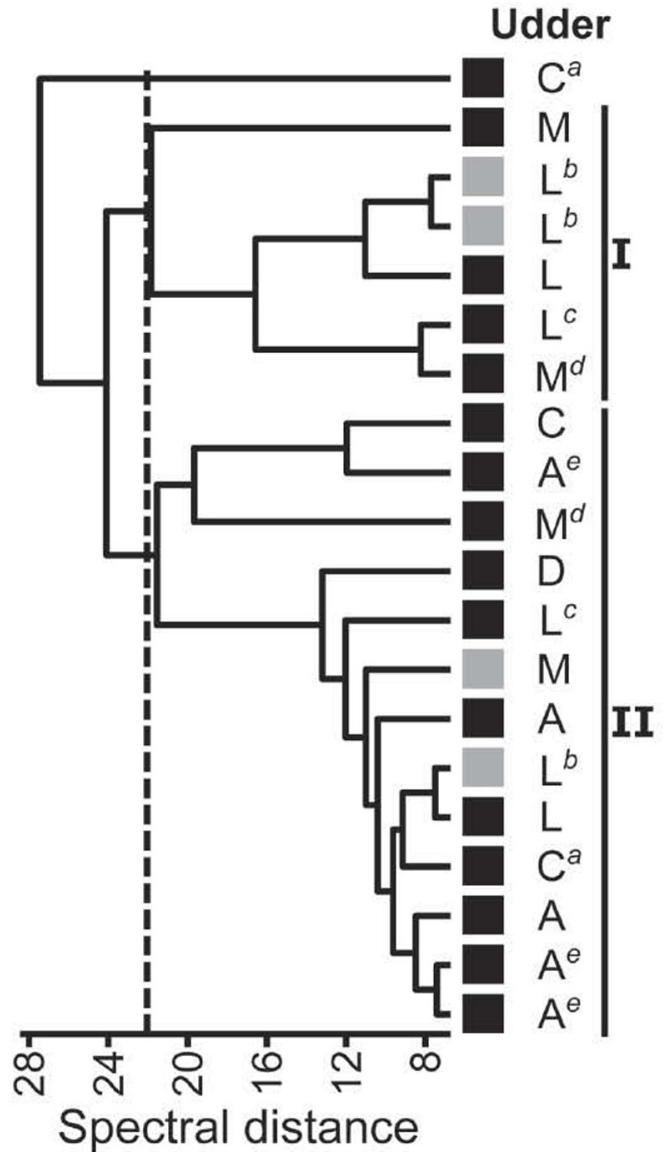

Figure 2. Study 2: (A) Distribution of distinct isolated species from intramammary abscesses and aspirated milk samples; and (B) Hierarchical cluster analysis of matrix-assisted laser desorption ionization time-of-flight mass spectra of Staphylococcus aureus isolated from intramammary abscesses and aspirated milk samples. The indicated clusters (I and II) are defined at a spectral distance cut off of 22 . Isolates with the same superscript were isolated from the same abscess. 
cific strains are related to specific disease presentation. Similarly, closely related strains of Staph. aureus have been associated with both subclinical and gangrenous mastitis in sheep, and the difference in clinical outcome was attributed to a relatively small number of genetic loci (Vautor et al., 2009; Le Maréchal et al., 2011). So it is possible that a more detailed investigation of isolates from the current study would reveal differences between isolates from different sampling sites.

Analysis of milk from ewes without any signs of disease in the current study would have been informative to establish whether Staph. aureus was also present in the milk of such ewes, although Mørk et al. (2012) reported only $1.5 \%$ Staph. aureus positive milk samples from 265 clinically normal ewes. Mørk et al. (2012) also reported Staph. aureus on skin, nares, and lambs' tonsils and proposed that these sites were reservoirs for Staph. aureus. Whereas the epidemiology and transmission routes of Staph. aureus (and other bacterial species) in suckler sheep flocks remain to be fully characterized, the detection of similar strains of Staph. aureus in glands that were unaffected, acutely and chronically diseased, suggests that one, or all, could be a source of potentially infectious material. The nasal mucous membranes are considered the primary reservoir (Mørk et al., 2012), and the mammary gland could form a secondary reservoir, with suckling lambs potentially facilitating transmission to susceptible ewes.

The detection of a large number of bacterial species in cases of acute mastitis, intramammary abscesses, and in the milk of suckler ewes adds to our understanding of the species capable of colonizing and potentially infecting the ovine mammary gland. Many are able, at least temporarily, to be sequestered inside intramammary abscesses, and this ability might be one mechanism that these bacterial species use to evade host defenses and treatments, allowing them to persist within individuals and the flock. From a flock health perspective, ewes with chronic mastitis are therefore a potential risk factor for future acute and chronic disease, although the magnitude of risk cannot be determined from the current data. To more fully characterize the relationships between acute and chronic disease, future studies should aim to investigate all forms of IMI and apparently healthy glands in ewes in a flock.

\section{CONCLUSIONS}

A large number of bacterial species were present in acute mastitis, intramammary abscesses, and milk of suckler ewes, and a high degree of overlap was present between the species detected at different sites. One species of bacteria tended to dominate each abscess and case of acute mastitis, and Staph. aureus dominated all
3 locations. Whereas closely related strains of Staph aureus were detected in intramammary abscesses and milk from the same mammary gland, and the affected and unaffected glands of ewes with acute mastitis, no strains were specifically linked with disease states. The results from the current study suggest that affected and unaffected glands of ewes with chronic or acute mastitis are a reservoir of Staph. aureus for susceptible ewes.

\section{ACKNOWLEDGMENTS}

This work was funded in part by a grant from EBLEX [English Beef and Lamb Executive; now named Agriculture and Horticulture Development Board (AHDB) Beef and Lamb, Kenilworth, UK] to L. E. Green and a BBSRC (Biotechnology and Biological Sciences Research Council, Swindon, UK) Research Experience Placement to Z. N. Willis (grant no. BB/J014532/1). The funding agencies did not influence the study design, sample collection, data analysis and interpretation, report writing, and decision to submit the article for publication. We are grateful to Andrew Bradley and Barbara Payne of Quality Milk Management Services (Easton, Wells, UK) for instrument access, and to Selene Huntley and Selin Cooper (University of Warwick, Coventry, UK) and Julia Smith (Bruker UK Ltd., Coventry, UK) for advice and technical assistance.

\section{REFERENCES}

Alatoom, A. A., S. A. Cunningham, S. M. Ihde, J. Mandrekar, and R. Patel. 2011. Comparison of direct colony method versus extraction method for identification of Gram-positive cocci by use of Bruker Biotyper matrix-assisted laser desorption ionization-time of flight mass spectrometry. J. Clin. Microbiol. 49:2868-2873. http:// dx.doi.org/10.1128/JCM.00506-11.

Arsenault, J., P. Dubreuil, R. Higgins, and D. Belanger. 2008. Risk factors and impacts of clinical and subclinical mastitis in commercial meat-producing sheep flocks in Quebec, Canada. Prev. Vet. Med. 87:373-393. http://dx.doi.org/10.1016/j.prevetmed.2008.05.006.

Brook, I. 2002. Abscesses. Pages 153-168 in Polymicrobial Diseases. K. A. Brogden and J. M. Guthmiller, ed. ASM Press, Washington, DC.

Bruker Daltonik GmbH. 2011. MALDI Biotyper 3.0 User Manual. Bruker Daltonik GmbH, Coventry, UK.

Calvo-Bado, L. A., B. B. Oakley, S. E. Dowd, L. E. Green, G. F Medley, A. Ul-Hassan, V. Bateman, W. Gaze, L. Witcomb, R. Grogono-Thomas, J. Kaler, C. L. Russell, and E. M. H. Wellington. 2011. Ovine pedomics: The first study of the ovine foot $16 \mathrm{~S}$ rRNA-based microbiome. ISME J. 5:1426-1437. http://dx.doi. org/10.1038/ismej.2011.25.

Cheng, A. G., A. C. DeDent, O. Schneewind, and D. Missiakas. 2011. A play in four acts: Staphylococcus aureus abscess formation. Trends Microbiol. 19:225-232. http://dx.doi.org/10.1016/j. tim.2011.01.007.

Cheng, A. G., M. McAdow, H. K. Kim, T. Bae, D. M. Missiakas, and O. Schneewind. 2010. Contribution of coagulases towards Staphylococcus aureus disease and protective immunity. PLoS Pathog. 6:e1001036. http://dx.doi.org/10.1371/journal.ppat.1001036.

Dice, L. R. 1945. Measures of the amount of ecologic association between species. Ecology 26:297-302. http://dx.doi.org/10.2307/1932409. 
Hunt, K. M., J. A. Foster, L. J. Forney, U. M. Schutte, D. L. Beck, Z. Abdo, L. K. Fox, J. E. Williams, M. K. McGuire, and M. A. McGuire. 2011. Characterization of the diversity and temporal stability of bacterial communities in human milk. PLoS ONE 6:e21313 http://dx.doi.org/10.1371/journal.pone.0021313.

Jones, J. E. T., and G. H. Watkins. 1998. Studies on mastitis in sheep at the Royal Veterinary College. Pages 83-90 in Proc. Sheep Veterinary Society Spring Meeting, Scarborough, Yorkshire, UK. Sheep Veterinary Society, Penicuik, UK.

Kuehn, J. S., P. J. Gorden, D. Munro, R. Rong, Q. Dong, P. J. Plummer, C. Wang, and G. J. Phillips. 2013. Bacterial community profiling of milk samples as a means to understand culture-negative bovine clinical mastitis. PLoS ONE 8:e61959. http://dx.doi. org/10.1371/journal.pone.0061959.

Lasch, P., C. Fleige, M. Stammler, F. Layer, U. Nubel, W. Witte, and G. Werner. 2014. Insufficient discriminatory power of MALDITOF mass spectrometry for typing of Enterococcus faecium and Staphylococcus aureus isolates. J. Microbiol. Methods 100:58-69. http://dx.doi.org/10.1016/j.mimet.2014.02.015.

Le Maréchal, C., D. Hernandez, J. Schrenzel, S. Even, N. Berkova, R. Thiéry, E. Vautor, J. R. Fitzgerald, P. François, and Y. Le Loir. 2011. Genome sequences of two Staphylococcus aureus ovine strains that induce severe (strain O11) and mild (strain O46) mastitis. J. Bacteriol. 193:2353-2354. http://dx.doi.org/10.1128/JB.0004511.

Marogna, G., S. Rolesu, S. Lollai, S. Tola, and G. Leori. 2010. Clinical findings in sheep farms affected by recurrent bacterial mastitis. Small Rumin. Res. 88:119-125. http://dx.doi.org/10.1016/j. smallrumres.2009.12.019.

Moore, J. E., Y. Maeda, J. Xu, B. C. Millar, P. H. Herold, V. M. J. Browne-Lauwers, C. E. Goldsmith, A. Loughrey, P. J. Rooney, J. S. Elborn, and M. Matsuda. 2008. Employment of $16 \mathrm{~S}$ rDNA gene sequencing techniques for improved identification of difficult-toidentify bacterial veterinary pathogens. World J. Microb. Biot. 24:1227-1232. http://dx.doi.org/10.1007/s11274-007-9573-6.
Mørk, T., B. Kvitle, and H. J. Jørgensen. 2012. Reservoirs of Staphylococcus aureus in meat sheep and dairy cattle. Vet. Microbiol. 155:81-87. http://dx.doi.org/10.1016/j.vetmic.2011.08.010.

Mørk, T., S. Waage, T. Tollersrud, B. Kvitle, and S. Sviland. 2007. Clinical mastitis in ewes; bacteriology, epidemiology and clinical features. Acta Vet. Scand. 49:23 http://dx.doi.org/10.1186/17510147-49-23.

Oikonomou, G., M. L. Bicalho, E. Meira, R. E. Rossi, C. Foditsch, V. S. Machado, A. G. V. Teixeira, C. Santisteban, Y. H. Schukken, and R. C. Bicalho. 2014. Microbiota of cow's milk; distinguishing healthy, sub-clinically and clinically diseased quarters. PLoS ONE 9:e85904 http://dx.doi.org/10.1371/journal.pone.0085904.

Oikonomou, G., V. S. Machado, C. Santisteban, Y. H. Schukken, and R. C. Bicalho. 2012. Microbial diversity of bovine mastitic milk as described by pyrosequencing of metagenomic 16s rDNA. PLoS ONE 7:e47671. http://dx.doi.org/10.1371/journal.pone.0047671.

Onnasch, H., A. Healy, P. Brophy, A. Kinsella, and M. Doherty. 2002. A study of mastitis in Irish sheep. Res. Vet. Sci. 72(Suppl. 1):42. (Abstr.)

Saratsis, P. L. Leontides, A. Tzora, C. Alexopoulos, and G. C. Fthenakis. 1998. Incidence risk and aetiology of mammary abnormalities in dry ewes in 10 flocks in southern Greece. Prev. Vet. Med. 37:173-183. http://dx.doi.org/10.1016/S0167-5877(98)00111-1.

Smith, E. M., E. M. Monaghan, S. J. Huntley, and L. E. Green. 2011. Preliminary investigation into the effect of freezing and a cryopreservant on the recovery of mastitis pathogens from ewe milk. J. Dairy Sci. 94:4850-4855. http://dx.doi.org/10.3168/jds.20104076.

Vautor, E., J. Cockfield, C. Le Maréchal, Y. Le Loir, M. Chevalier, D. A. Robinson, R. Thiéry, and J. Lindsay. 2009. Difference in virulence between Staphylococcus aureus isolates causing gangrenous mastitis versus subclinical mastitis in a dairy sheep flock. Vet. Res. 40:56. http://dx.doi.org/10.1051/vetres/2009039.

Watts, J. L. 1988. Etiological agents of bovine mastitis. Vet. Microbiol. 16:41-66. http://dx.doi.org/10.1016/0378-1135(88)90126-5. 